Atmos. Chem. Phys., 18, 10407-10418, 2018

https://doi.org/10.5194/acp-18-10407-2018

(C) Author(s) 2018. This work is distributed under

the Creative Commons Attribution 4.0 License.

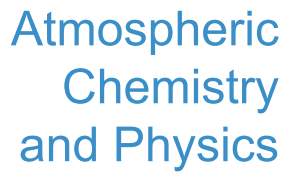

(c) (i)

\title{
Chemical characterization of laboratory-generated tar ball particles
}

\author{
Ádám Tóth ${ }^{1}$, András Hoffer ${ }^{2}$, Mihály Pósfai ${ }^{1}$, Tibor Ajtai ${ }^{3}$, Zoltán Kónya ${ }^{4,5}$, Marianne Blazsó ${ }^{6}, Z_{\text {Zsuzsanna Czégény }}{ }^{6}$, \\ Gyula Kiss ${ }^{2}$, Zoltán Bozóki ${ }^{3}$, and András Gelencsér ${ }^{1,2}$ \\ ${ }^{1}$ Department of Earth and Environmental Sciences, University of Pannonia, Veszprém, P.O. Box 158, 8201, Hungary \\ ${ }^{2}$ MTA-PE Air Chemistry Research Group, Veszprém, P.O. Box 158, 8201, Hungary \\ ${ }^{3}$ MTA-SZTE Research Group on Photoacoustic Spectroscopy, Szeged, Dóm tér 9, 6720, Hungary \\ ${ }^{4}$ Department of Applied and Environmental Chemistry, University of Szeged, Szeged, Rerrich Béla tér 1, 6720, Hungary \\ ${ }^{5}$ MTA-SZTE Reaction Kinetics and Surface Chemistry Research Group, Szeged, Rerrich Béla tér 1, 6720, Hungary \\ ${ }^{6}$ MTA-TTK Institute of Materials and Environmental Chemistry, Budapest, P.O. Box 286, 1519, Hungary
}

Correspondence: András Gelencsér (gelencs@almos.uni-pannon.hu)

Received: 5 February 2018 - Discussion started: 6 March 2018

Revised: 13 June 2018 - Accepted: 2 July 2018 - Published: 23 July 2018

\begin{abstract}
The chemical properties of laboratory-generated tar ball (Lab-TB) particles produced from dry distillate (wood tars) of three different wood species in the laboratory were investigated by analytical techniques that had never been used before for their characterization. The elemental compositions of laboratory-generated tar balls (LabTBs) from three tree species were very similar to one another and to those characteristic of atmospheric tar balls (TBs) collected from the savanna fire during the SAFARI 2000 sampling campaign. The $\mathrm{O} / \mathrm{C}$ and $\mathrm{H} / \mathrm{C}$ molar ratios of the generated Lab-TBs were at the upper limit characteristic of soot particles. The Fourier transform infrared spectroscopy (FTIR) spectra of the generated Lab-TBs were very similar to one another as well and also showed some similarity with those of atmospheric humic-like substances (HULIS). The FT-IR measurements indicated that Lab-TBs have a higher proportion of aromatic structure than HULIS and the oxygen atoms of Lab-TBs are mainly found in hydroxyl and keto functional groups. Whereas Raman activity was detected in the starting materials of the Lab-TBs (wood tars) in the range of 1000-1800 $\mathrm{cm}^{-1}$, the Raman spectra of TBs were dominated by two pronounced bands with intensity maxima near 1580 ( $\mathrm{G}$ band) and $1350 \mathrm{~cm}^{-1}$ (D band), indicating the presence of $\mathrm{sp}^{2}$-hybridized carbon structures and disorder in them, respectively. In the Py-GC-MS chromatograms of the Lab-TBs mostly aromatic compounds (aromatic hydrocarbons, oxygenated aromatics and heterocyclic aromatics) were identified in accordance with the results of Raman and FT-IR spectroscopy. According to organic carbon / elemental
\end{abstract}

carbon (OC / EC) analysis using EUSAAR_2 thermal protocol, $22 \%$ of the total carbon content of Lab-TBs was identified as EC, contrary to expectations based on the current understanding that negligible if any EC is present in this subfraction of the brown carbon family. Our results suggest that spherical atmospheric TBs with high $\mathrm{C} / \mathrm{O}$ molar ratios are closer to BC in many of their properties than to weakly absorbing HULIS.

\section{Introduction}

Atmospheric tar balls (TBs) comprise a unique class of carbonaceous aerosol particles emitted during biomass burning (Pósfai et al., 2003, 2004; Adachi and Buseck, 2011). TBs are understood to be part of the family of atmospheric brown carbon (BrC) (Hand et al., 2005; Andreae and Gelencsér, 2006), as they absorb light in the visible range of the solar spectrum yet are distinctly different from BC in microstructure, morphology and in other properties (as summarized by Petzold et al., 2013). Since these particles are fairly abundant in biomass burning plumes and are able to absorb solar radiation quite efficiently in the visible (Hand et al., 2005; Alexander et al., 2008) and up to the near-IR range (Hoffer et al., 2017), TBs may have a considerable effect on the Earth radiation budget (Chung et al., 2012). It should be noted here that other authors (Chakrabarty et al., 2010; China et al., 2013; Sedlacek et al., 2017; Sedlacek III et al., 2018) found less absorbing "tar ball" particles with chemical properties (C / O 
ratio) and optical parameters resembling those of humic-like substances (HULIS). TBs can be unambiguously identified by electron microscopy as spherical amorphous particles externally mixed in relatively fresh biomass burning plumes (Pósfai et al., 2003, 2004; Adachi and Buseck, 2011). Unlike soot particles, TBs do not form chain-like aggregates of 20 $50 \mathrm{~nm}$ spherules and there are no turbostratic/concentrically wrapped graphitic layers in their microstructure. Their sizes range from 30 to $500 \mathrm{~nm}$ in geometric diameter (Pósfai et al., 2004). Furthermore, TBs are refractory as they can withstand the high-energy electron beam of the transmission electron microscopy (TEM) in vacuum (Pósfai et al., 2004; Hand et al., 2005). In addition, elemental composition (C / O molar ratio) is also an important characteristic of TBs. Typical C / O molar ratios of atmospheric TBs are about 9-10, as determined by TEM with energy-dispersive $\mathrm{X}$-ray spectroscopy (TEM-EDS). It should be noted that in some studies the term "tar ball" is used for combustion particles that are nonspherical and have a lower $\mathrm{C} / \mathrm{O}$ molar ratio (Chakrabarty et al., 2016). That is why in this paper we apply the term "tar balls" also to non-perfectly spherical particles.

Albeit TBs are abundant in biomass burning plumes globally, very little is known about their chemical composition mainly because in biomass smoke TBs coexist with various other particle types (e.g. organic particles with inorganic inclusions, soot) from which they cannot be separated physically. Thus, the chemical properties of TBs can only be studied by single-particle analytical techniques such as TEMEDS or SEM-EDS (Li et al., 2003; Pósfai et al., 2003, 2004; Hand et al., 2005; Niemi et al., 2006; Adachi and Buseck, 2011; Chakrabarty et al., 2016; Adachi et al., 2017; Cong et al., 2009, 2010; China et al., 2013; Chakrabarty et al., 2006, 2010; Semeniuk et al., 2007), TEM with electron energy-loss spectroscopy (TEM-EELS) (Hand et al., 2005, Adachi and Buseck, 2011), and near-edge X-ray absorption fine-structure spectroscopy (NEXAFS) using a synchrotron source (Tivanski et al., 2007). In our previous works (Tóth et al., 2014; Hoffer et al., 2016) an experimental setup had been developed for the generation of TB particles in the laboratory without the concurrent emission of other combustion products. The structural characteristics (homogeneity) and the elemental composition of the TB particles generated by this experimental system were highly similar to those of atmospheric TBs published by Pósfai et al. (2004) and Adachi and Buseck et al. (2011) as the Lab-TBs have homogenous internal structure without core and concentrically wrapped graphitic layers. Similarly to the atmospheric TBs the generated LabTB particles were also refractory under the electron beam of the TEM. Their particle diameter extended up to $360 \mathrm{~nm}$ measured by a DMPS system. The high $\mathrm{C} / \mathrm{O}$ molar ratios (see later) of the Lab-TB particles were very similar to those found by other authors for atmospheric TBs (C / O: 8-10; Pósfai et al., 2004; Niemi et al., 2006). However, it should be noted here that other authors (Tivanski et al., 2007; China et al., 2013) reported atmospheric TBs with significantly lower
C / O ratios (1-2). In the present study the chemical properties of the TBs produced in the laboratory were investigated by several analytical techniques which have never been applied for the characterization of TBs. The analytical methods deployed were direct elemental analysis (CHNSO), organic carbon / elemental carbon (OC / EC) thermal-optical analysis (TOA), pyrolysis-gas chromatography-mass spectrometry (Py-GC-MS), Fourier transform infrared spectroscopy (FT-IR) and Raman spectroscopy. The results of the analyses were directly compared to those obtained by other studies using the same techniques for atmospheric humic-like substances (HULIS), or humic acid and soot (BC) with a view to locate the chemical properties of refractory TBs (with high $\mathrm{C} / \mathrm{O}$ ratio) in the continuum of carbonaceous aerosol constituents.

\section{Experimental section}

The generation of TB particles in the laboratory was carried out as described in Hoffer et al. (2016). Briefly, Lab-TBs were produced from the liquid tarry condensates obtained by dry distillation of wood chips of Norway spruce (Picea abies), European turkey oak (Quercus cerris) and black locust (Robinia pseudoacacia), separately. The concentrated aqueous phase of the tarry condensates (wood tars) was nebulized to produce tar droplets which were first exposed to a "thermal shock" by passing them through a heated (at $650{ }^{\circ} \mathrm{C}$ ) quartz tube, then cooled and dried with dry filtered air. The optical and the morphological properties of the particles generated from Norway spruce and black locust were described by Hoffer et al. (2017). The size distribution of the generated particles was measured by a DMPS system (Hoffer et al., 2017). The shapes of the particles (investigated by TEM) generated from European turkey oak were mostly distorted spheres. In this case the majority of the particles were likely deliquescent upon collision with the collection surface. The morphologies of these particles were very similar to those of the freshly formed atmospheric TBs (or to the precursor particles of the TBs) collected from biomass burning smoke $3-4 \mathrm{~km}$ away from fire, presented by Adachi and Buseck (2011) in their Fig. 4c. Although the shape of the particles generated from European turkey oak was not perfectly spherical on the TEM grids, we assume that prior to impaction they were likely spherical. Based on this assumption and the fact that their chemical properties (e.g. elemental composition and IR spectra; see later) were similar to those of the other laboratory-generated TB particles, we refer to these particles also as Lab-TBs. The generated particles were collected on different sampling substrates: on TEM grids (lacey Formvar/carbon TEM copper grid of 200 mesh, Ted Pella Inc., USA), on pre-baked double (front and backup) quartz filters (QMA, $\varnothing 47 \mathrm{~mm}$, Whatman) and on pre-cleaned aluminium foils using a Berner cascade impactor (Wang and John, 1988). In the case of the impactor samples 
we used the samples collected on stage 2 (aerodynamic diameter between 125 and $250 \mathrm{~nm}$ ), representing about half (based on the DMPS measurements $\sim 37 \%, \sim 47 \%, \sim 59 \%$, for the turkey oak, black locust and Norway spruce, respectively) of the mass of the generated particles. The morphologies and the elemental compositions $(\mathrm{C}, \mathrm{O}, \mathrm{N}, \mathrm{S})$ of individual TB particles from different wood species were studied in brightfield TEM images obtained using a Philips CM20 TEM operated at $200 \mathrm{kV}$ accelerating voltage. The electron microscope had an attached ultra-thin-window Bruker Quantax Xray detector that allowed the energy-dispersive $\mathrm{X}$-ray analysis (EDS) of individual particles. The relative concentrations of $\mathrm{C}$ and $\mathrm{O}$ were determined using sensitivity ratios $(k$ factors) derived from EDS spectra acquired from a standard (a stoichiometric dolomite $\left(\mathrm{CaMg}\left[\mathrm{CO}_{3}\right]_{2}\right)$ sample). Nitrogen was not determined quantitatively. We took great care both in this and all former studies to analyse the compositions of only those particles that had sufficient volumes over holes, avoiding any contribution from the support film in the EDS spectra.

The elemental (C, H, N, S, O) compositions of the aqueous phases of the concentrated wood tar samples (the starting material for Lab-TB generation) and those of the Lab-TBs were determined using a EuroVector EA3000 CHNS/O elemental analyser. The carrier gas was helium (He) (purity: 4.6; Messer) with a flow rate of $110 \mathrm{~L} \mathrm{~min}^{-1}$, the temperature of the reactor tube and that of the $\mathrm{GC}$ oven were 980 and $70^{\circ} \mathrm{C}$, respectively. The instrument was equipped with a thermal conductivity detector (TCD). The measurements of CHNS and oxygen content of samples were carried out separately from quartz filters, and all analyses were performed in duplicate. The portions of filters with area of $1 \mathrm{~cm}^{2}$ were packed in double tin $(\varnothing 5 \times 9 \mathrm{~mm})$ capsules in the case of the CHNS analysis while in the case of the oxygen analysis the samples were wrapped in double silver capsules $(\varnothing 5 \times 9 \mathrm{~mm})$. The data were corrected for blanks taken from backup quartz filters of the same size in double tin/silver capsules. The calibration for these elements was carried out using reference standard materials (acetanilide, SOIL\#5, SOIL NCS-2) from EuroVector, Italy.

The OC / EC thermal-optical analysis of Lab-TBs was performed by a Model-4 Semi-Continuous OC-EC Field Analyzer (Sunset Laboratory Inc., USA). The aerosol samples on quartz filters $(\varnothing 13.06 \mathrm{~mm})$ were analysed following the EUSAAR_2 protocol (Cavalli et al., 2010). The data were corrected for blanks taken from backup quartz filters of same size.

The Lab-TB samples collected on quartz filters were investigated using Py-GC-MS. The analyses were performed with a Pyroprobe 2000 pyrolyser (CDS Analytical) interfaced directly to a gas chromatograph-mass spectrometer (Agilent 6890A/5973). The portions of sample filters with areas of $0.5 \mathrm{~cm}^{2}$ were heated from 250 to $600^{\circ} \mathrm{C}$ at a heating rate of $1{ }^{\circ} \mathrm{C} \mathrm{ms}^{-1}$ and held for $20 \mathrm{~s}$ in the pyrolyser. High-purity $\mathrm{He}$ (purity: 5.0; Linde) as a carrier gas was used at a con- trolled flow rate of $20 \mathrm{~mL} \mathrm{~min}^{-1}$ to flush the pyrolysis products into a DB-1701capillary column $(30 \mathrm{~m} \times 0.25 \mathrm{~mm}$ ID, $0.25 \mu \mathrm{m}$ film thickness, Agilent). The GC injector was set in splitless mode with an inlet temperature of $250^{\circ} \mathrm{C}$. The temperature of the column was kept at $40^{\circ} \mathrm{C}$ for $2 \mathrm{~min}$, then increased at a heating rate of $10^{\circ} \mathrm{C} \mathrm{min}^{-1}$ to $280^{\circ} \mathrm{C}$ and held there for $5 \mathrm{~min}$. Temperatures of the GC-MS interface and the detector were 280 and $230^{\circ} \mathrm{C}$, respectively. The mass spectrometer was operated at $70 \mathrm{eV}$ with a mass detection in the $m / z$ range of $15-350$.

The characteristic functional groups of wood tar and LabTB samples collected on aluminium foils were examined using specular reflection FT-IR technique. The spectra of the samples were recorded on a Bruker Vertex 70 FT-IR spectrometer coupled with a Hyperion 2000 IR microscope with $15 \times(\mathrm{NA}=0.4)$ specular reflection objective. Spectra were recorded over the range of wave number $4000-400 \mathrm{~cm}^{-1}$ at room temperature using 128 scans at $2 \mathrm{~cm}^{-1}$ resolution.

The wood tar and Lab-TB samples collected on aluminium foils were also investigated by Raman spectrometry. Raman spectra were recorded with a Thermo Scientific DXR Raman microscope at excitation wavelength $\left(\lambda_{0}\right)$ of $532 \mathrm{~nm}$, applying maximum $10 \mathrm{~mW}$ laser power, with the laser beam focused using a $50 \times$ objective lens, resulting in a spot size of $\sim 1 \mu \mathrm{m}$. Typically, 20 scans were recorded and averaged with $4 \mathrm{~cm}^{-1}$ resolution in the $200-1800 \mathrm{~cm}^{-1}$ range. The peak fittings of Raman spectra (in the range between 1000 and $1800 \mathrm{~cm}^{-1}$ ) were executed after multi-point baseline correction using by the GRAMS/AI (Version 7.02) software.

\section{Results}

\subsection{Elemental composition of laboratory-generated TBs}

According to the CHNSO analysis the mean $\mathrm{C}, \mathrm{H}, \mathrm{N}$, and O contents of TB samples $(n=3)$ on quartz filter were $82 \%$ (RSD: $0.5 \%$ ), $4 \%$ (RSD: $6.7 \%$ ), $3 \%$ (RSD: $39 \%$ ), and $11 \%$ (RSD: $9.2 \%$ ) by mass, respectively. Sulfur was below the detection limit.

Table 1 summarizes the average $\mathrm{O} / \mathrm{C}$ and $\mathrm{H} / \mathrm{C}$ molar ratios of wood tars and Lab-TBs produced from the three wood types, as determined by CHNSO elemental analysis. For comparison, the $\mathrm{O} / \mathrm{C}$ molar ratios obtained for individual particles by TEM measurements are also given. The $\mathrm{O} / \mathrm{C}$ molar ratios of the Lab-TB particles obtained from three different tree species were very similar to each other and to the values obtained from TEM-EDS analyses. The $\mathrm{H} / \mathrm{C}$ molar ratio was relatively low (between 0.51 and 0.58 ), indicating that the Lab-TBs consist mostly of unsaturated, aromatic and oxygenated organic compounds. It should be noted that wood tars (starting material for TB generation) exhibited significantly higher $\mathrm{O} / \mathrm{C}$ and $\mathrm{H} / \mathrm{C}$ molar ratios ( 0.182 and 1.215 , respectively), which strongly suggests that 
the "thermal shock" employed during Lab-TB generation (as described in Hoffer et al., 2016) has markedly increased the degree of aromatization (Francioso et al., 2011). It is also possible that some residual water is present in the raw tar, which is then removed in the thermal process. Its presence may also be a plausible explanation of the markedly different shapes and $\mathrm{C} / \mathrm{O}$ ratios reported for atmospheric TB particles in the literature.

In order to compare the elemental composition of LabTBs with those of soot, HULIS and atmospheric TBs, a van Krevelen diagram is plotted (Fig. 1). For the atmospheric TBs measured in earlier studies using TEM-EDS (Pósfai et al., 2004), SEM-EDS (Chakrabarty et al., 2010; China et al., 2013), and NEXAFS (Tivanski et al., 2007), only the available $\mathrm{O} / \mathrm{C}$ molar ratios are presented in the diagram. It can be clearly seen that the average $\mathrm{O} / \mathrm{C}$ molar ratio of our Lab-TB particles is very similar to that of atmospheric TBs examined by Pósfai et al. (2004), whereas it is lower than those obtained by some other authors (Tivanski et al., 2007; Chakrabarty et al., 2010; China et al., 2013). This difference in compositions may result from differences in the formation temperatures and/or atmospheric processing of the TBs. China et al. (2013) collected slightly aged (1-2 h) particles from the smoldering phase of the Las Conchas fire in northern New Mexico, USA. Chakrabarty et al. (2010) investigated particles from the smoldering combustion of dry duffs, whereas Tivanski et al. (2007) observed aged TBs during episodes characterized by high particle light-scattering coefficients. In contrast to these authors, Pósfai et al. (2003, 2004) measured TB particles from both flaming and smoldering savanna fires, although the authors mention that the distinction between different burning stages was often not straightforward, since flaming and smoldering stages of the burn could be present simultaneously in adjacent areas. The uncertain identification of burning stages notwithstanding, these observations suggest that several types of TBs may exist with different $\mathrm{O} / \mathrm{C}$ molar ratios, depending on the formation temperature and the temperature and duration of the heat shock that the particles are exposed to, and/or on the degree of atmospheric processing.

However, when comparing the elemental compositions of our Lab-TBs to that of HULIS, both the O / C (0.094-0.109) and the $\mathrm{H} / \mathrm{C}(0.511-0.584)$ molar ratios of our Lab-TBs were substantially lower than those reported for HULIS samples (O / C: 0.455-0.563; H / C: 1.431-1.537) (Krivácsy et al., 2001; Kiss et al., 2002; Salma et al., 2007). The O / C molar ratio of other atmospheric TBs varies widely and in some cases compares better with the $\mathrm{O} / \mathrm{C}$ molar ratio of HULIS. The $\mathrm{O} / \mathrm{C}$ and $\mathrm{H} / \mathrm{C}$ molar ratios of TBs identified by Pósfai et al. (2004) from savanna fires, as well as our Lab-TBs (O / C: 0.094-0.109; H / C: 0.511-0.584) are close to the upper limit of those characteristic of soot $(\mathrm{O} / \mathrm{C}: \sim 0.12 ; \mathrm{H} / \mathrm{C}$ : $\sim 0.38$ ).

As expected from the above results, the mean carbon to mass conversion factor of our Lab-TBs (1.21; RSD: 0.5\%) is between that of HULIS (1.81-1.93; Krivácsy et al., 2001; Kiss et al., 2002; Salma et al., 2007) and soot samples (1.041.15; Akhter et al., 1985; Clague et al., 1999).

\subsection{Characterization by FT-IR spectroscopy}

The FT-IR spectra of wood tar and Lab-TB samples are characterized by broad and overlapping bands (Fig. 2). The figure also shows that the FT-IR spectra of Lab-TBs produced from the three different wood species are much more similar to one another than the spectra from different wood tars. Large differences in the IR spectra of wood tars can be observed particularly in the fingerprint region $\left(1400-500 \mathrm{~cm}^{-1}\right)$; in contrast, being exposed to a heat shock, the Lab-TBs from different sources became chemically similar to one another.

The FT-IR spectra of wood tars and Lab-TBs show a very broad band between 3600 and $3000 \mathrm{~cm}^{-1}$ (might be assigned to $\mathrm{OH}$-stretching of phenol and/or hydroxyl groups) and a smaller band in the region between 3000 and $2780 \mathrm{~cm}^{-1}$, which can be attributed to asymmetric and symmetric $\mathrm{C}-\mathrm{H}$ stretching of methyl and methylene aliphatic groups (Coates, 2000; Graber and Rudich, 2006; Yang et al., 2007). In the spectra of Lab-TBs the $\mathrm{sp}^{2}$-aromatic $\mathrm{C}-\mathrm{H}$ stretching at $3060 \mathrm{~cm}^{-1}$ (Coates, 2000; Cain et al., 2010; Santamaría et al., 2006) is more pronounced than in the spectra of wood tars, indicating the increased aromaticity. The spectra of wood tars and Lab-TBs are dominated by two strong bands at $\sim 1700$ and at $\sim 1605 \mathrm{~cm}^{-1}$, assigned to $\mathrm{C}=\mathrm{O}$ stretching and $\mathrm{C}=\mathrm{C}$ stretching of aromatic rings (with overlapping $\mathrm{C}=\mathrm{O}$ stretching), respectively (Coates, 2000; Graber and Rudich, 2006; Santamaría et al., 2006; Cain et al., 2010). The ratio of these two bands is the opposite in the two sample types; the intensity of the aromatic $\mathrm{C}=\mathrm{C}$ stretching increases relative to the $\mathrm{C}=\mathrm{O}$ stretching in Lab-TBs.

The region between 1450 and $1380 \mathrm{~cm}^{-1}$ can be assigned to aliphatic or aromatic methyl and methylene bending (Craddock et al., 2015; Coates, 2000; Santamaría et al., 2006; Cain et al., 2010).

The possible aromatic $\mathrm{C}-\mathrm{C}$ and $\mathrm{C}-\mathrm{H}$ plane deformation bands in the region between 1300 and $1000 \mathrm{~cm}^{-1}$ overlap with the band of the $\mathrm{C}-\mathrm{O}$ single bond. The broad band at $1220 \mathrm{~cm}^{-1}$ probably belongs to the $\mathrm{C}-\mathrm{O}$ stretching of phenolic hydroxyl groups in FT-IR spectra of wood tar and Lab-TB samples (Coates, 2000; Yang et al., 2007), whereas the peaks at $\sim 920 ; \sim 1040, \sim 1110$, and $\sim 1321 \mathrm{~cm}^{-1}$ might correspond to the $\mathrm{C}-\mathrm{H}$ bending of carbohydrate, to $\mathrm{C}-\mathrm{O}$ stretch in the $\mathrm{C}-\mathrm{OH}$ in carbohydrate structure, to stretching of the $\mathrm{C}-$ $\mathrm{O}$ of the $\mathrm{C}-\mathrm{O}-\mathrm{C}$ linkage, and $\mathrm{O}-\mathrm{H}$ bending of $\mathrm{C}-\mathrm{OH}$ group, respectively (Santamaría et al., 2006; Yang et al., 2007; Cain et al., 2010; Carletti et al., 2010; Anjos et al., 2015).

By comparing the IR spectra of Lab-TBs with those of HULIS it can be concluded that they show large-scale similarity, since the characteristic bands, the aliphatic and aromatic $\mathrm{C}-\mathrm{H}$, aromatic $\mathrm{C}=\mathrm{C}$, hydroxyl and keto groups (Krivácsy et al., 2001; Kiss et al., 2002; Duarte et al., 
Table 1. Oxygen to carbon $(\mathrm{O} / \mathrm{C})$ and hydrogen to carbon $(\mathrm{H} / \mathrm{C})$ molar ratios of laboratory-generated TBs and wood tar samples measured by TEM-EDS (from analysis of 12 particles from each sample) and by CHNSO elemental analyser. The numbers in parentheses represent the relative standard deviation (RSD\%) of the parameters. * Data from Hoffer et al. (2017).

\begin{tabular}{lrrr}
\hline & $\begin{array}{r}\text { O / C molar ratio } \\
\text { (by TEM-EDS) }\end{array}$ & $\begin{array}{r}\text { O / C molar ratio } \\
\text { (by CHNSO) }\end{array}$ & $\begin{array}{r}\text { H / C molar ratio } \\
\text { (by CHNSO) }\end{array}$ \\
\hline Lab-TB - black locust & $0.110(12 \%)^{*}$ & $0.094(6 \%)$ & $0.584(3 \%)$ \\
Lab-TB - Norway spruce & $0.108(7 \%)^{*}$ & $0.109(8 \%)$ & $0.511(22 \%)$ \\
Lab-TB - turkey oak & $0.111(9 \%)$ & $0.094(5 \%)$ & $0.543(1 \%)$ \\
Lab-TB sample average & $0.110(10 \%)$ & $0.099(10 \%)$ & $0.546(7 \%)$ \\
Wood tar sample average & no data & $0.182(9 \%)$ & $1.215(4 \%)$ \\
\hline
\end{tabular}

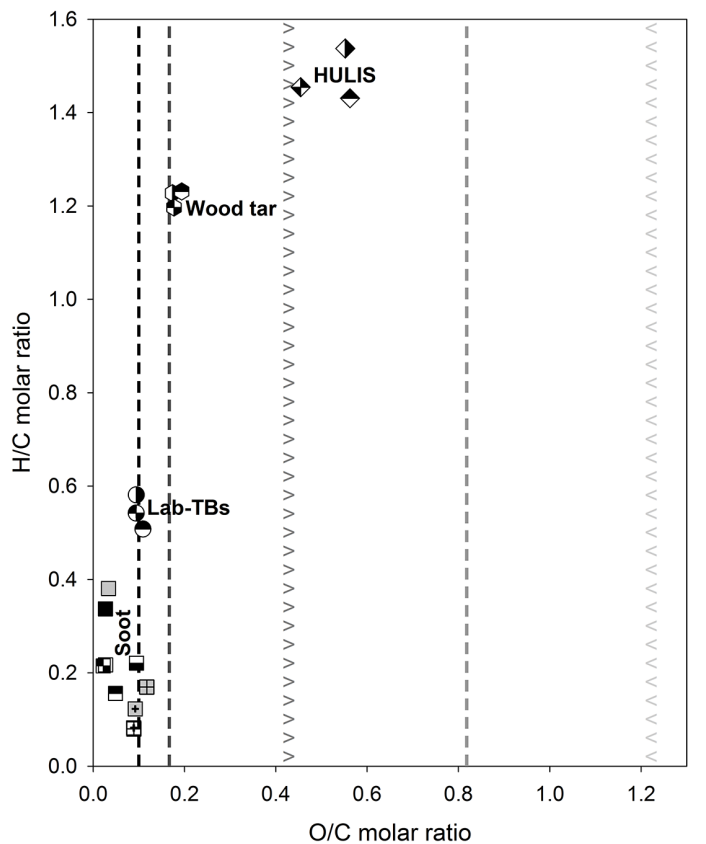

O/C ratio (upper limit, EDS) of TB by China et al. (2013) O/C ratio (STXM/NEXAFS) of TB by Tivanski et al. (2007)

O/C ratio (lower limit, EDS) of TB by China et al. (2013)

1 O/C ratio (EDS) of TB by Chakrabarty et al. (2010)

I O/C ratio (EDS) of TB by Pósfai et al. (2004)

HULIS (EA w/o O) by Krivácsy et al. (2001)

$\Rightarrow$ HULIS (EA w/o O) by Kiss et al. (2002)

HULIS (EA w/o O) by Salma et al. (2007)

- Lab-TB - black locust (EA w O)

Lab-TB - Norway spruce (EA w O)

- Lab-TB - turkey oak (EA w O)

- Wood tar - black locust (EA w O)

- Wood tar - Norway spruce (EA w O)

Wood tar - turkey oak (EA wO)

- Soot -1 (EA) by Akhter et al. (1985)

- Soot -2 (EA) by Akhter et al. (1985)

- Soot - 1 (EA w/o O) by Clague et al. (1999)

$\square$ Soot - 1 - extracted (EA w/o O) by Clague et al. (1999)

- Soot - 2 (EA w/o O) by Clague et al. (1999)

Soot -2 - extracted (EA w/o O) by Clague et al. (1999)

$\rightarrow$ Soot - 1 (EA w O) by Collura et al. (2005)

7 Soot -1 - extracted (EA w O) by Collura et al. (2005)

田 Soot - 2 (EA w O) by Collura et al. (2005)

$\boxplus$ Soot - 2 - extracted (EA w O) by Collura et al. (2005)

Figure 1. Van Krevelen diagram of different soot (Akhter et al., 1985; Clague et al., 1999; Collura et al., 2005), Lab-TB, wood tar and HULIS (Krivácsy et al., 2001; Kiss et al., 2002; Salma et al., 2007) samples. The elemental compositions were measured by energy-dispersive X-ray spectroscopy (EDS), scanning transmission X-ray microscopy with near-edge X-ray absorption fine structure spectroscopy (STXM/NEXAF), or different elemental analysis techniques with or without direct oxygen measurement (EA, EA w O, EA w/o O).

2005; Graber and Rudich, 2006; Kristensen et al., 2015) are present, but the intensity ratios of the $\mathrm{C}=\mathrm{O}\left(\sim 1700 \mathrm{~cm}^{-1}\right)$ and the $\mathrm{C}=\mathrm{C}\left(\sim 1605 \mathrm{~cm}^{-1}\right)$ bands are the opposite. This implies that Lab-TBs might have a higher proportion of aromatic structure than HULIS, and the composition of HULIS is probably more similar to the wood tars in this respect. Another difference between the spectra of Lab-TBs and HULIS is that the HULIS spectra contain a very broad band (assigned to $\mathrm{O}-\mathrm{H}$ stretching in carboxyl group), which occurs at 3400 to $2400 \mathrm{~cm}^{-1}$ and often overlaps with $\mathrm{C}-\mathrm{H}$ stretching. Since this characteristic broad band is missing in the spectra of both wood tar and Lab-TB samples, the presence of the carboxylic groups in the samples was not confirmed.

The FT-IR spectra of Lab-TBs also differ from those of soot: the band representative of the acetylenic group at $3300 \mathrm{~cm}^{-1}$ is absent in the spectra of TBs and the spectra of soot do not contain the bands of $\mathrm{OH}$-stretching (Cain et al., 2010; Santamaría et al., 2006; Santamaria et al., 2010).

\subsection{Raman spectroscopy}

Raman spectroscopy was used to characterize the short-range order in the molecular structure of Lab-TBs. Whereas Raman activity was not detected (either because of the lower amount of the substances or because of their chemical composition) in the wood tar samples in the range of $1000-1800 \mathrm{~cm}^{-1}$, the Raman spectra of laboratory-generated TBs were dominated by two pronounced bands with intensity maxima near 1580 and $1350 \mathrm{~cm}^{-1}$. This double peak was deconvoluted by the five-band fitting procedure first proposed by Sadeczky et al. (2005), but it was found that instead of using four Lorentzian $\left(\mathrm{G}, D_{1}, D_{2}, D_{4}\right)$ and one Gaussian $\left(D_{3}\right)$ peaks, 

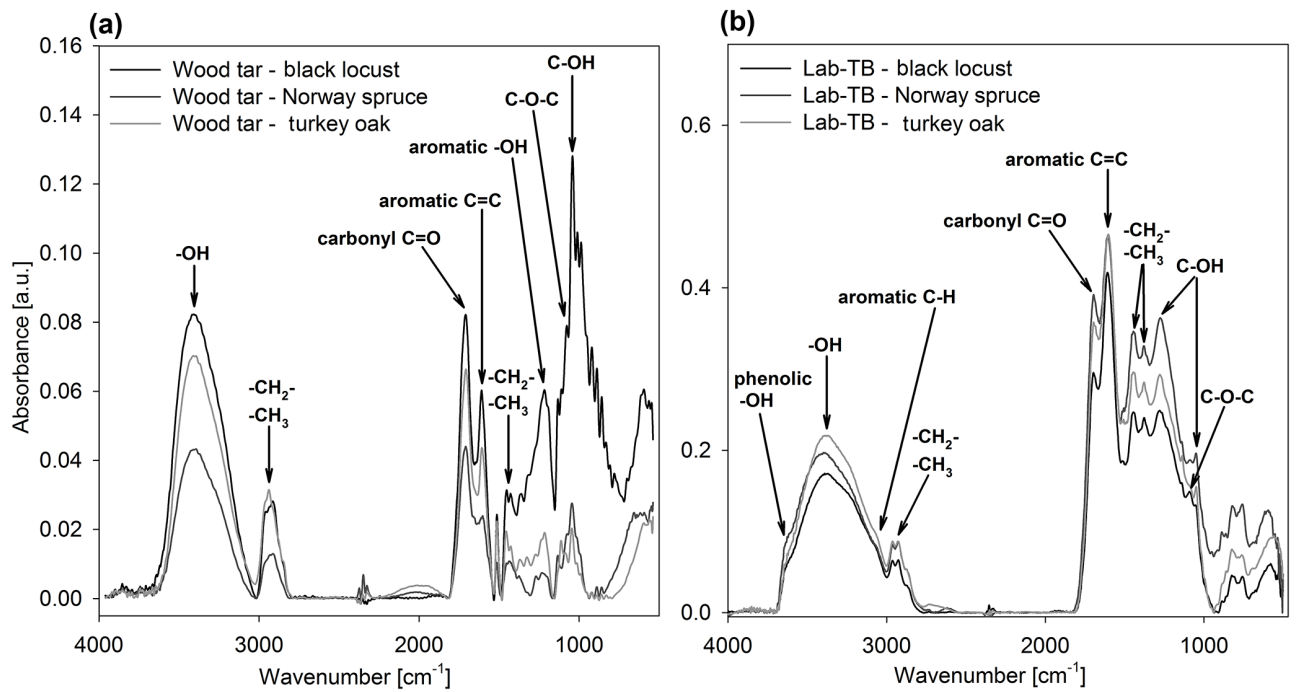

Figure 2. FT-IR spectra of (a) wood tars and (b) laboratory-generated TBs (Lab-TBs) produced from different wood species.
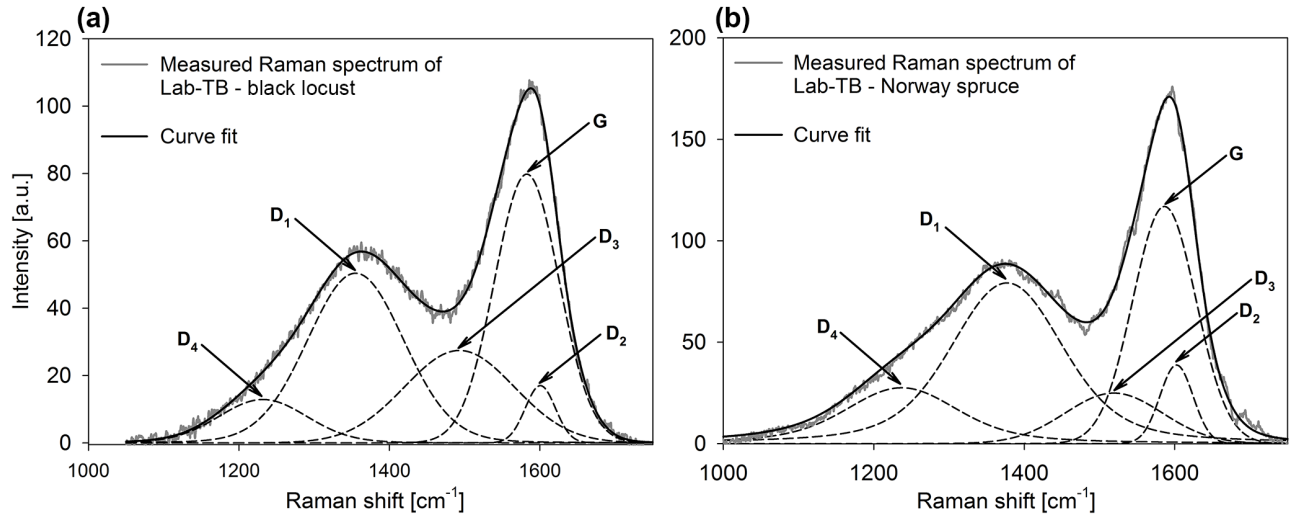

Figure 3. Curve fit with five bands for the first-order Raman spectra (excitation wavelength: $\lambda_{0}=532 \mathrm{~nm}$ ) of laboratory-generated tar ball (Lab-TB) particles, produced from (a) black locust and (b) Norway spruce, using as proposed by Catelani et al. (2014) for carbonaceous materials.

the best fit was obtained with five Voigt functions, similarly to Catelani et al. (2014). The Raman spectra and examples for the peak deconvolution (in the range between 1000 and $1800 \mathrm{~cm}^{-1}$ ) of the Lab-TBs are shown in Fig. 3. The Raman spectra of the Lab-TBs generated from turkey oak were not evaluated, since the peak fitting was uncertain due to a reduced signal-to-noise ratio. The presence of the $\mathrm{G}$ band in the Raman spectra of Lab-TBs indicates that Lab-TBs contain an aromatic layer built up from $\mathrm{sp}^{2}$-hybridized carbon atoms, whereas the existence of the $\mathrm{D}$ bands points to the presence of poorly organized carbonaceous materials. Kristensen et al. (2015) investigated the Raman and IR spectra of different HULIS samples. The Raman spectra of HULIS exhibited sloping backgrounds, and the presence of a small peak at $1630 \mathrm{~cm}^{-1}$ was attributed to the stretching of aromatics. The height of this peak was somewhat higher in the case of a fulvic acid standard indicating the higher aromaticity of this compound compared to the HULIS extracted from urban and rural samples. Ivleva et al. (2007) investigated the Raman spectra of a humic acid standard and those of soot samples. The obtained $\mathrm{G}$ and $\mathrm{D}$ bands were more pronounced in the spectra of these components than in the spectra of the HULIS. The Raman spectra of the macromolecular humic acid (purified, Carl Roth GmbH, Karlsruhe, Germany) investigated by Ivleva et al. (2007) were very similar to those of our Lab-TBs.

\subsection{Py-GC-MS measurements}

With Py-GC-MS of the Lab-TB samples, approximately 40 compounds were identified (Table 2). The pyrolysis products were identified by comparison of their mass spectra with the standard mass spectra in the NIST 02 Library (NIST/EPA/NIH Mass Spectral Library, 2002). 
Table 2. Identified components from Py-GC-MS chromatogram of Lab-TBs produced from different wood species, compared with the identified pyrolytic products of hexane, gasoline, diesel, and wood soot (Song and Peng, 2010), and humic acid extracted from particulate matter (Subbalakshmi et al., 2000).

\begin{tabular}{|c|c|c|c|c|c|c|c|c|}
\hline \multirow[b]{2}{*}{ Name of pyrolytic compounds } & \multicolumn{3}{|c|}{ Examined samples } & \multicolumn{5}{|c|}{ Reference samples } \\
\hline & $\begin{array}{c}\text { Black locust } \\
\text { Lab-TB }\end{array}$ & $\begin{array}{c}\text { Norway spruce } \\
\text { Lab-TB }\end{array}$ & $\begin{array}{c}\text { Turkey oak } \\
\text { Lab-TB }\end{array}$ & $\begin{array}{c}\text { Hexane } \\
\text { soot }\end{array}$ & $\begin{array}{l}\text { Gasoline } \\
\text { soot }\end{array}$ & $\begin{array}{c}\text { Diesel } \\
\text { soot }\end{array}$ & $\begin{array}{l}\text { Wood } \\
\text { soot }\end{array}$ & $\begin{array}{c}\text { Humic } \\
\text { acid }\end{array}$ \\
\hline \multicolumn{9}{|c|}{ Aromatic hydrocarbons } \\
\hline \multicolumn{9}{|c|}{ 1-ring aromatic hydrocarbons } \\
\hline Benzene & $\times$ & $\times$ & $\times$ & & & & & $\times$ \\
\hline$o / m / p$-Dimethylbenzene & $\times$ & $x^{*}$ & $\times$ & $\times$ & $\times$ & $\times$ & $\times$ & $\times$ \\
\hline$\alpha$-Methylstyrene & $\times$ & $\times$ & $x^{*}$ & & & & & $\times$ \\
\hline Styrene & $\times$ & $x^{*}$ & $x^{*}$ & $\times$ & $\times$ & $\times$ & $\times$ & $\times$ \\
\hline Toluene & $\times$ & $\times$ & $\times$ & $\times$ & $\times$ & $\times$ & $\times$ & \\
\hline \multicolumn{9}{|c|}{ 2-ring aromatic hydrocarbons } \\
\hline Biphenyl & $\times$ & $\times$ & $\times$ & $\times$ & $\times$ & $\times$ & $\times$ & $\times$ \\
\hline 1,6-Dimethylnaphthalene & $\times$ & $\times$ & $\times$ & & & & & $\times$ \\
\hline 2,3-Dimethylnaphthalene & $\times$ & $x$ & $\times$ & & & & & $\times$ \\
\hline 2,7-Dimethylnaphthalene & $\times$ & $\times$ & $\times$ & & & & & $\times$ \\
\hline Indene & $x$ & $\times$ & $\times$ & $\times$ & $\times$ & & & \\
\hline 2-Methylindene & $\times$ & $\times$ & $\times$ & & & & & \\
\hline 1-Methylnaphtalene & $x$ & $x$ & $x$ & $\times$ & $\times$ & & $x$ & \\
\hline 2-Methylnaphtalene & $\times$ & $\times$ & $\times$ & $\times$ & $\times$ & & $\times$ & \\
\hline 3-Methyl-1H-indene & $x$ & $\times$ & $\times$ & & & & & \\
\hline Naphthalene & $\times$ & $\times$ & $\times$ & $\times$ & $\times$ & $\times$ & $\times$ & \\
\hline \multicolumn{9}{|c|}{ 3-ring aromatic hydrocarbons } \\
\hline Acenaphthylene & $\times$ & $\times$ & $\times$ & $x$ & & & & \\
\hline Anthracene & & & & $\times$ & $x$ & & $\times$ & \\
\hline Fluorene & $\times$ & $\times$ & $\times$ & $\times$ & $\times$ & & $\times$ & \\
\hline 1-Methyl-9H-fluorene & & & $\times$ & & & & & \\
\hline 4-Methyl-9H-fluorene & & & $\times$ & & & & & \\
\hline Phenanthrene & & & & $\times$ & $\times$ & $\times$ & $\times$ & \\
\hline \multicolumn{9}{|c|}{ 4-ring aromatics hydrocarbons } \\
\hline Fluoranthene & & & & $\times$ & $\times$ & & $\times$ & \\
\hline Pyrene & & & & $\times$ & $\times$ & $\times$ & $\times$ & \\
\hline \multicolumn{9}{|c|}{ 5-ring aromatic hydrocarbons } \\
\hline Benzo[mno]fluoranthene & & & & $\times$ & $\times$ & & $\times$ & \\
\hline \multicolumn{9}{|c|}{ Oxygenated aromatics } \\
\hline \multicolumn{9}{|c|}{ 1-ring oxygenated aromatics } \\
\hline Acetophenone & $\times$ & $\times$ & $\times$ & & & & & \\
\hline Benzaldehyde & $x$ & $x^{*}$ & $x^{*}$ & & & & & $\times$ \\
\hline 2,4-Dihydroxy-3,6-dimethylbenzaldehyde & & $\times$ & $\times$ & & & & & \\
\hline 2,3-Dimethylphenol & $\times$ & $\times$ & $\times$ & & $\times$ & & & \\
\hline 2,4-Dimethylphenol & $\times$ & $\times$ & $\times$ & & $\times$ & & & \\
\hline 2,5-Dimethylphenol & $\times$ & $\times$ & $\times$ & & $\times$ & & & \\
\hline 2,6-Dimethylphenol & & $\times$ & $\times$ & & $\times$ & & & \\
\hline 3,4-Dimethylphenol & $\times$ & & & & $\times$ & & & \\
\hline 2,6-Dimethoxyphenol & & & & & & & & $\times$ \\
\hline 2-Ethylphenol & & $\times$ & $\times$ & & & & & $\times$ \\
\hline 2-Methoxy-4-methylphenol & & & & & & & & $\times$ \\
\hline 2-Methoxyphenol & & & & & & & & $\times$ \\
\hline 2-Methylphenol & $\times$ & $\times$ & $\times$ & & $x$ & & & $\times$ \\
\hline 4-Methylphenol & $\times$ & $\times$ & $\times$ & & $\times$ & & & $\times$ \\
\hline Phenol & $\times$ & $\times$ & $\times$ & $\times$ & $\times$ & $\times$ & $\times$ & $\times$ \\
\hline \multicolumn{9}{|c|}{ 2-ring oxygenated aromatics } \\
\hline 2,3-Dihydro-1H-inden-1-one & $x^{*}$ & $\times$ & $x^{*}$ & & & & & \\
\hline Phthalic acid anhydride & $\times$ & $x$ & $\times$ & & & & & $\times$ \\
\hline
\end{tabular}


Table 2. Continued.

\begin{tabular}{|c|c|c|c|c|c|c|c|c|}
\hline \multirow[b]{2}{*}{ Name of pyrolytic compounds } & \multicolumn{3}{|c|}{ Examined samples } & \multicolumn{5}{|c|}{ Reference samples } \\
\hline & $\begin{array}{l}\text { Black locust } \\
\text { Lab-TB }\end{array}$ & $\begin{array}{c}\text { Norway spruce } \\
\text { Lab-TB }\end{array}$ & $\begin{array}{l}\text { Turkey oak } \\
\text { Lab-TB }\end{array}$ & $\begin{array}{l}\text { Hexane } \\
\text { soot }\end{array}$ & $\begin{array}{l}\text { Gasoline } \\
\text { soot }\end{array}$ & $\begin{array}{c}\text { Diesel } \\
\text { soot }\end{array}$ & $\begin{array}{l}\text { Wood } \\
\text { soot }\end{array}$ & $\begin{array}{c}\text { Humic } \\
\text { acid }\end{array}$ \\
\hline \multicolumn{9}{|c|}{ Oxygen-containing heterocyclic aromatics } \\
\hline \multicolumn{9}{|c|}{ 1-ring oxygen-containing heterocyclic aromatics } \\
\hline 3-Furancarboxaldehyde & & & $x$ & & & & & $x$ \\
\hline 5-Methyl-2-furaldehyde & $x^{*}$ & $x$ & $x^{*}$ & & & & & $x$ \\
\hline \multicolumn{9}{|c|}{ 2-ring oxygen-containing heterocyclic aromatics } \\
\hline 2-Methylbenzofuran & $x$ & $x$ & $x$ & & & & & \\
\hline 7-Methylbenzofuran & $x$ & $x$ & $x$ & & & & & \\
\hline Benzofuran & $x$ & $\times$ & $\times$ & & $x$ & $\times$ & $x$ & \\
\hline \multicolumn{9}{|c|}{ 3-ring oxygen-containing heterocyclic aromatics } \\
\hline Dibenzofuran & $x$ & $x$ & $x$ & & & & $x$ & \\
\hline
\end{tabular}

* The concentration of the given component is the same as on the back-up filter in this sample.

In the pyrograms of the Lab-TB samples, mainly aromatic compounds have been identified in accordance with the results of Raman and FT-IR spectroscopy, and indirectly with the results of the elemental analysis. Aromatic hydrocarbons (benzene, alkyl-, alkenyl-substituted benzenes) and smaller (2-3 aromatic rings) polycyclic aromatic hydrocarbons (PAHs), oxygenated aromatics (phenol, alkylsubstituted phenols) and heterocyclic aromatics (phthalic anhydride, furan, benzofuran, dibenzofuran and their derivatives) were identified. Many of the above-mentioned components have been identified using the same analytical technique from humic acid (extracted by sodium hydroxide solution and precipitated with hydrochloric acid from urban aerosol) and different (hexane, gasoline, diesel and wood) soot samples (see Table 2) in previous studies (Subbalakshmi et al., 2000; Song and Peng, 2010). Comparing the chromatograms of humic acid, Lab-TBs and soot, significant differences occur in the quality (different numbers of aromatic rings) and quantity (number of compounds) of PAH components. The pyrograms of humic acid contain only few small (2-ring) PAHs, e.g. naphthalene and its derivatives (methyland dimethyl-naphthalene), whereas in the pyrograms of the Lab-TBs larger (3-ring) PAHs can be also found. On the other hand, in the pyrograms of soot samples (Song and Peng, 2010) both smaller (2-3-ring) and larger (4-5-ring) PAHs were also found, but the latter compounds were not detected in the pyrograms of Lab-TBs.

\subsection{OC / EC thermal-optical analysis}

Since TBs belong to the $\mathrm{BrC}$ fraction of carbonaceous aerosol (Hoffer et al., 2016), their EC content is expected to be very small or even negligible. Since the results of Raman spectroscopy indicated some structural similarities with atmospheric soot, we determined the apparent EC content of Lab-TBs by standard OC / EC analysis. The results of
OC / EC thermal-optical analysis of Lab-TBs which were produced from three different wood species are given in Table 3 .

The EC / TC (total carbon) ratio for Lab-TBs varied from 0.17 to 0.32 (on average: 0.22 ; RSD: $39.1 \%$ ), which is far from being negligible, contrary to expectations. It is also important to note that there is an uncertainty in the position of the split point in the OC / EC measurement. In the case of the TBs, the criterion that $\mathrm{OC}$ should be non-absorbing is not met; thus, the absorption of $\mathrm{BrC}$ lowers the baseline of the transmittance. Consequently, the split point is set earlier and a larger EC signal is measured (Chen et al., 2015). The thermogram of TBs produced from Norway spruce shows that the detector signal returns to the baseline neither after the fourth OC peak nor after the pyrolytic carbon peak, and thus a notable fraction of pyrolytic carbon (PC) is identified as EC (see Fig. 4). According to Piazzalunga et al. (2011) the EC / TC ratio of the water-soluble fraction of urban background aerosol (which contains the HULIS fraction as well) measured with the EUSAAR_2 protocol was 0.02. On the other hand Han et al. (2007) investigated the EC / TC ratio of different SRM soot and chars with the IMPOOVE TOR method. For the soot samples EC / TC ratios of 0.68-0.96 were obtained, whereas values for the char samples ranged between 0.53 and 0.85 .

\section{Conclusions}

We have studied the chemical properties of Lab-TBs using analytical techniques that had never been used for the characterization of atmospheric TBs and compared the results with those obtained for soot, HULIS, and humic acid. The elemental compositions of the Lab-TB particles generated from different wood species were very similar to one another and their $\mathrm{O} / \mathrm{C}$ molar ratio was similar to those characteristic of 
Table 3. Organic carbon (OC), elemental carbon (EC), total carbon (TC) content and ratio of elemental carbon to total carbon content (EC / TC) (RSD\% of 3 Lab-TB samples) of laboratory-generated tar balls (Lab-TBs) on quartz filters (spot $\varnothing 13.06 \mathrm{~mm}$ ) obtained by the EUSAAR_2 protocol.

\begin{tabular}{lrrrr}
\hline & $\begin{array}{r}\text { OC } \\
{\left[\mu \mathrm{g} \mathrm{cm}^{-2}\right]}\end{array}$ & $\begin{array}{r}\text { EC } \\
{\left[\mu \mathrm{g} \mathrm{cm}^{-2}\right]}\end{array}$ & $\begin{array}{r}\text { TC } \\
{\left[\mu \mathrm{g} \mathrm{c}^{-2}\right]}\end{array}$ & EC / TC \\
\hline Lab-TB - black locust & 9.0 & 4.2 & 13.2 & 0.32 \\
Lab-TB - Norway spruce & 14.1 & 2.9 & 17.1 & 0.17 \\
Lab-TB - turkey oak & 14.2 & 2.9 & 17.1 & 0.17 \\
Lab-TB sample average & & & & 0.22 (RSD: 39\%) \\
\hline
\end{tabular}

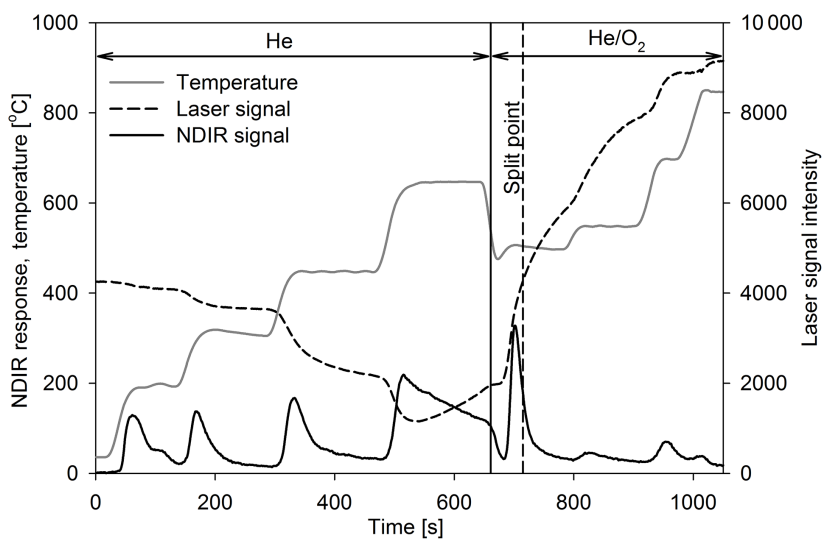

Figure 4. Thermogram from analysis of Lab-TBs produced from Norway spruce, measured by thermal-optical analysis (TOA) obtained by the EUSAAR_2 protocol.

atmospheric TBs formed in savanna fires. In the van Krevelen diagram (plot of O / C vs. H / C molar ratio) soot and HULIS are confined to rather narrow regimes and are distinctly different from TBs which have highly variable $\mathrm{O} / \mathrm{C}$ molar ratios, depending on the conditions prevalent during their formation and/or subsequent atmospheric processing. The $\mathrm{O} / \mathrm{C}$ and $\mathrm{H} / \mathrm{C}$ molar ratios of the Lab-TBs (and the $\mathrm{O} / \mathrm{C}$ ratio of atmospheric TBs identified from savanna fires) are much lower than those of HULIS and closer to the upper-bound characteristic of soot. The FT-IR spectra of the different LabTBs were also similar to one another and also to some extent to the spectra of HULIS. However, the oxygen atoms in Lab-TBs are found to be largely present in components of keto and hydroxyl functional groups, with very few if any in carboxyl groups occurring in Lab-TBs, unlike in HULIS. While the starting material of Lab-TBs (wood tars) were Raman inactive in the range of $1000-1800 \mathrm{~cm}^{-1}$, the appearance of $\mathrm{G}$ (characteristic of ordered $\mathrm{sp}^{2}$-hybridized carbon structures) and $\mathrm{D}$ bands (characteristic of structural disorder in $\mathrm{sp}^{2}$-hybridized carbon systems) in the Raman spectra of Lab-TBs indicated the presence of some short-range order in molecular structures. In the Py-GC-MS pyrograms of different Lab-TBs mostly aromatic compounds were identified. While pyrograms of Lab-TBs did not indicate the presence of larger condensed aromatic structures (with 4-5 aromatic rings) which are characteristic of soot, they showed several naphthalene derivatives and 3-ring condensed aromatics which are absent among the pyrolysis products of HULIS. Using the EUSAAR_2 thermal protocol, on average $22 \%$ of the total carbon of the Lab-TBs was found to be elemental carbon (EC), contrary to the expected negligible if any EC in a sub-fraction of the brown carbon family. Our results have demonstrated chemical differences between wood tars and an important sub-fraction of TBs and have helped to position them along the organic-to-graphitic carbon continuum of combustion aerosols. In this regard, the combination of all analytical results presents an array of supporting chemical evidence that perfectly spherical atmospheric TBs with $\mathrm{C} / \mathrm{O}$ molar ratio around 10 are closer to $\mathrm{BC}$ in many of their properties than to weakly absorbing HULIS. Since atmospheric aging of particles is not simulated in our laboratory experiment, just a fast "heat shock" is applied to the primary droplets (to which ejected particles may also be exposed in a biomass fire); therefore, chemically different TBs may occur in biomass smoke plumes depending on the mechanisms and conditions of post-emission (photo)chemical transformations. Since the optical properties of the particles are closely related to their chemical composition, the findings of the present study imply (in harmony with the findings of several independent studies on the optical properties of TBs) that spherical TBs with high $\mathrm{C} / \mathrm{O}$ ratio are indeed quite strongly light-absorbing aerosol particles and likely play an important role in the global radiation budget.

Data availability. Data used in this study are available from the first author upon request (toth.adam@almos.uni-pannon.hu).

Author contributions. ÁT and AH produced and collected the aerosol samples. ÁT, AH, MP, GK, ZC, MB, AT, ZK, and ZB performed and/or coordinated the analytical measurements. ÁT, AH, $\mathrm{MP}$, and AG were involved in the scientific interpretation and discussion of the results as well as in manuscript preparation. All coauthors commented on the paper. 
Competing interests. The authors declare that they have no conflict of interest.

Acknowledgements. This paper was supported by the János Bolyai Research Scholarship of the Hungarian Academy of Sciences. The work was supported by the project GINOP-2.3.2-15-2016-00055. The project was realized with the support of the European Union, with the co-funding of the European Social Fund. This work was also supported by the project GINOP-2.3.2-15-2016-00036 and EFOP-3.6.1-16-2016-00014. The authors would like to thank Koppány Levente Juhász and Viktor Havasi for their assistance with this project.

Edited by: Alexander Laskin

Reviewed by: four anonymous referees

\section{References}

Adachi, K. and Buseck, P. R.: Atmospheric tar balls from biomass burning in Mexico, J. Geophys. Res.-Atmos., 116, D05204, https://doi.org/10.1029/2010jd015102, 2011.

Adachi, K., Sedlacek III, A. J., Kleinman, L., Chand, D., Hubbe J. M., and Buseck, P. R.: Volume changes upon heating of aerosol particles from biomass burning using transmission electron microscopy, Aerosol Sci. Tech., 52, 45-56, https://doi.org/10.1080/02786826.2017.1373181, 2017.

Akhter, M. S., Chughtai, A. R., and Smith, D. M.: The structure of hexane soot I: spectroscopic studies, Appl. Spectrosc., 39, 143$153,1985$.

Alexander, D. T. L., Crozier, P. A., and Anderson, J. R.: Brown carbon spheres in East Asian outflow and their optical properties, Science, 321, 833-836, https://doi.org/10.1126/science.1155296, 2008.

Andreae, M. O. and Gelencsér, A.: Black carbon or brown carbon? The nature of light-absorbing carbonaceous aerosols, Atmos. Chem. Phys., 6, 3131-3148, https://doi.org/10.5194/acp-63131-2006, 2006.

Anjos, O., Campos, M. G., Ruiz, P. C., and Antunes, P.: Application of FTIR-ATR spectroscopy to the quantification of sugar in honey, Food Chem., 169, 218-223, https://doi.org/10.1016/j.foodchem.2014.07.138, 2015.

Cain, J. P., Gassman, P. L., Wang, H., and Laskin A.: Micro-FTIR study of soot chemical composition - evidence of aliphatic hydrocarbons on nascent soot surfaces, Phys. Chem. Chem. Phys., 12, 5206-5218, https://doi.org/10.1039/b924344e, 2010.

Carletti, C., Roldán, M. L., Francioso, O., Nardi, S., and Sanchez-Cortes, S.: Structural characterization of humiclike substances with conventional and surface-enhanced spectroscopic techniques, J. Mol. Struct., 982, 169-175, https://doi.org/10.1016/j.molstruc.2010.08.028, 2010.

Catelani, T., Pratesi, G., and Zoppi, M.: Raman characterization of ambient airborne soot and associated mineral phases, Aerosol Sci. Tech., 48, 13-21, https://doi.org/10.1080/02786826.2013.847270, 2014.

Cavalli, F., Viana, M., Yttri, K. E., Genberg, J., and Putaud, J.-P.: Toward a standardised thermal-optical protocol for measuring atmospheric organic and elemental carbon: the EUSAAR protocol,
Atmos. Meas. Tech., 3, 79-89, https://doi.org/10.5194/amt-3-792010, 2010.

Chakrabarty, R. K., Moosmüller, H., Garro, M. A., Arnott, W. P., Walker, J., Susott, R. A., Babbitt, R. E., Wold, C. E., Lincoln, E. N., and Hao, W. M.: Emissions from the laboratory combustion of wildland fuels: particle morphology and size, J. Geophys. Res.-Atmos., 111, D07204, https://doi.org/10.1029/2005JD006659, 2006.

Chakrabarty, R. K., Moosmüller, H., Chen, L.-W. A., Lewis, K., Arnott, W. P., Mazzoleni, C., Dubey, M. K., Wold, C. E., Hao, W. M., and Kreidenweis, S. M.: Brown carbon in tar balls from smoldering biomass combustion, Atmos. Chem. Phys., 10, 63636370, https://doi.org/10.5194/acp-10-6363-2010, 2010.

Chakrabarty, R. K., Gyawali, M., Yatavelli, R. L. N., Pandey, A., Watts, A. C., Knue, J., Chen, L.-W. A., Pattison, R. R., Tsibart, A., Samburova, V., and Moosmüller, H.: Brown carbon aerosols from burning of boreal peatlands: microphysical properties, emission factors, and implications for direct radiative forcing, Atmos. Chem. Phys., 16, 3033-3040, https://doi.org/10.5194/acp-16-3033-2016, 2016.

Chen, L.-W. A., Chow, J. C., Wang, X. L., Robles, J. A., Sumlin, B. J., Lowenthal, D. H., Zimmermann, R., and Watson, J. G.: Multiwavelength optical measurement to enhance thermal/optical analysis for carbonaceous aerosol, Atmos. Meas. Tech., 8, 451461, https://doi.org/10.5194/amt-8-451-2015, 2015.

China, S., Mazzoleni, C., Gorkowski, K., Aiken, A. C., and Dubey, M. K.: Morphology and mixing state of individual freshly emitted wildfire carbonaceous particles, Nat. Commun., 4, 2122, https://doi.org/10.1038/ncomms3122, 2013.

Chung, C. E., Ramanathan, V., and Decremer D.: Observationally constrained estimates of carbonaceous aerosol radiative forcing, P. Natl. Acad. Sci. USA., 109, 11624-11629, https://doi.org/10.1073/pnas.1203707109, 2012.

Clague, A. D. H., Donnet, J., Wang, T. K., and Peng, J. C. M.: A comparison of diesel engine soot with carbon black, Carbon, 37, 1553-1565, 1999.

Coates, J.: Interpretation of infrared spectra, a practical approach, in: Encyclopedia of analytical chemistry, edited by: Meyers, R. A., John Wiley and Sons Ltd., Chichester, UK, 10815-10837, 2000.

Collura, S., Chaoui, N., Azambre, B., Finqueneisel, G., Heintz, O., Krzton, A., Koch, A., and Weber, J. V.: Influence of the soluble organic fraction on the thermal behaviour, texture and surface chemistry of diesel exhaust soot, Carbon, 43, 605-613, https://doi.org/10.1016/j.carbon.2004.10.026, 2005.

Cong, Z., Kang, S., Dong, S., and Zhang, Y.: Individual particle analysis of atmospheric aerosols at Nam Co, Tibetan plateau, Aerosol Air Qual. Res., 9, 323-331, https://doi.org/10.4209/aaqr.2008.12.0064, 2009.

Cong, Z., Kang, S., Dong, S., Liu, X., and Qin D.: Elemental and individual particle analysis of atmospheric aerosols from high Himalayas, Environ. Monit. Assess., 160, 323-335, https://doi.org/10.1007/s10661-008-0698-3, 2010.

Craddock, P. R., Doan, T. V. L., Bake, K., Polyakov, M., Charsky, A. M., and Pomerantz, A. E.: Evolution of kerogen and bitumen during thermal maturation via semi-open pyrolysis investigated by infrared spectroscopy, Energy Fuels, 29, 2197-2210, https://doi.org/10.1021/ef5027532, 2015. 
Duarte, R. M. B. O., Pio, C. A., and Duarte, A. C.: Spectroscopic study of the water-soluble organic matter isolated from atmospheric aerosols collected under different atmospheric conditions, Anal. Chim. Acta, 530, 7-14, https://doi.org/10.1016/j.aca.2004.08.049, 2005.

Francioso, O., Sanchez-Cortes, S., Bonora, S., Roldán, M. L., and Certini, G.: Structural characterization of charcoal size-fractions from a burnt Pinus pinea forest by FT-IR, Raman and surfaceenhanced Raman spectroscopies, J. Mol. Struct., 994, 155-162, https://doi.org/10.1016/j.molstruc.2011.03.011, 2011.

Graber, E. R. and Rudich, Y.: Atmospheric HULIS: How humiclike are they? A comprehensive and critical review, Atmos. Chem. Phys., 6, 729-753, https://doi.org/10.5194/acp-6-7292006, 2006.

Han, Y., Cao, J., Chow, J. C., Watson, J. G., An, Z., Jin, Z., Fung, K., and Liu, S.: Evaluation of the thermal/optical reflectance method for discrimination between char- and soot-EC, Chemosphere, 69 , 569-574, https://doi.org/10.1016/j.chemosphere.2007.03.024, 2007.

Hand, J. L., Malm, W. C., Laskin, A., Day, D., Lee, T., Wang, C., Carrico, C., Carrillo, J., Cowin, J. P., Collett Jr. J., and Iedema M. J.: Optical, physical, and chemical properties of tar balls observed during the Yosemite Aerosol Characterization Study, J. Geophys. Res.-Atmos., 110, D21210, https://doi.org/10.1029/2004JD005728, 2005.

Hoffer, A., Tóth, A., Nyiro-Kósa, I., Pósfai, M., and Gelencsér, A.: Light absorption properties of laboratory-generated tar ball particles, Atmos. Chem. Phys., 16, 239-246, https://doi.org/10.5194/acp-16-239-2016, 2016.

Hoffer, A., Tóth, Á., Pósfai, M., Chung, C. E., and Gelencsér, A.: Brown carbon absorption in the red and nearinfrared spectral region, Atmos. Meas. Tech., 10, 2353-2359, https://doi.org/10.5194/amt-10-2353-2017, 2017.

Ivleva, N. P., McKeon, U., Niessner, R., and Pöschl, U.: Raman microspectroscopic analysis of size-resolved atmospheric aerosol particle samples collected with an ELPI: soot, humic-like substances, and inorganic compounds, Aerosol Sci. Tech., 41, 655671, https://doi.org/10.1080/02786820701376391, 2007.

Kiss, Gy., Varga, B., Galambos, I., and Ganszky, I.: Characterization of water-soluble organic matter isolated from atmospheric fine aerosol, J. Geophys. Res.-Atmos., 107, 8339, https://doi.org/10.1029/2001JD000603, 2002.

Kristensen, T. B., Du, L., Nguyen, Q. T., Nøjgaard, J. K., Koch, C. B., Nielsen, O. F., Hallar, A. G., Lowenthal, D. H., Nekat, B., van Pinxteren, D., Herrmann, H., Glasius, M., Kjaergaard, H. G., and Bilde, M.: Chemical properties of HULIS from three different environments, J. Atmos. Chem., 72, 65-80, https://doi.org/10.1007/s10874-015-9302-8, 2015.

Krivácsy, Z. Gelencsér, A., Kiss, Gy., Mészáros, E., Molnár, Á., Hoffer, A., Mészáros, T., Sárvári, Zs.,Temesi, D., Varga, B., Baltensperger, U., Nyeki, S., and Weingartner, E.: Study on the chemical character of water soluble organic compounds in fine atmospheric aerosol at the Jungfraujoch, J. Atmos. Chem., 39, 235-259, https://doi.org/10.1023/A:1010637003083, 2001.

Li, J., Pósfai, M., Hobbs, P. V., and Buseck, P. R.: Individual aerosol particles from biomass burning in southern Africa: 2. Compositions and aging of inorganic particles, J. Geophys. Res.-Atmos., 108, 8484, https://doi.org/10.1029/2002JD002310, 2003.
Niemi, J. V., Saarikoski, S., Tervahattu, H., Mäkelä, T., Hillamo, R., Vehkamäki, H., Sogacheva, L., and Kulmala, M.: Changes in background aerosol composition in Finland during polluted and clean periods studied by TEM/EDX individual particle analysis, Atmos. Chem. Phys., 6, 5049-5066, https://doi.org/10.5194/acp6-5049-2006, 2006.

Petzold, A., Ogren, J. A., Fiebig, M., Laj, P., Li, S.-M., Baltensperger, U., Holzer-Popp, T., Kinne, S., Pappalardo, G., Sugimoto, N., Wehrli, C., Wiedensohler, A., and Zhang, X.-Y.: Recommendations for reporting "black carbon" measurements, Atmos. Chem. Phys., 13, 8365-8379, https://doi.org/10.5194/acp13-8365-2013, 2013.

Piazzalunga, A., Bernardoni, V., Fermo, P., Valli, G., and Vecchi, R.: Technical Note: On the effect of water-soluble compounds removal on EC quantification by TOT analysis in urban aerosol samples, Atmos. Chem. Phys., 11, 10193-10203, https://doi.org/10.5194/acp-11-10193-2011, 2011.

Pósfai, M., Simonics, R., Li, J., Hobbs, P. V., and Buseck, P. R.: Individual aerosol particles from biomass burning in southern Africa, 1, Compositions and size distributions of carbonaceous particles, J. Geophys. Res.-Atmos., 108, 8483, https://doi.org/10.1029/2002JD002291, 2003.

Pósfai, M., Gelencsér, A., Simonics, R., Arató, K., Li, J., Hobbs, P. V., and Buseck, P. R.: Atmospheric tar balls: Particles from biomass and biofuel burning, J. Geophys. Res.-Atmos., 109, D06213, https://doi.org/10.1029/2003JD004169, 2004.

Sadeczky, A., Muckenhuber, H., Grothe, H., Niessner, R., and Pöschl, U.: Raman microspectroscopy of soot and realted carbonaceous materials: spectral analysis and structural information, Carbon, 43, 1731-1742, https://doi.org/10.1016/j.carbon.2005.02.018, 2005.

Salma, I., Ocskay, R., Chi, X., and Maenhaut W.: Sampling artefacts, concentration and chemical composition of fine watersoluble organic carbon and humic-like substances in a continental urban atmospheric environment, Atmos. Environ., 41, 41064118, https://doi.org/10.1016/j.atmosenv.2007.01.027, 2007.

Santamaría, A., Mondragón, F., Molina, A., Marsh, N. D., Eddings, E., and Sarofim, G. A. F.: FT-IR and $1 \mathrm{H}$ NMR characterization of the products of an ethylene inverse diffusion flame, Combust. Flame, 146, 52-62, https://doi.org/10.1016/j.combustflame.2006.04.008, 2006.

Santamaria, A., Yang, N., Eddings, E., and Mondragon, F.: Chemical and morphological characterization of soot and soot precursors generated in an inverse diffusion flame with aromatic and aliphatic fuels, Combust. Flame, 157, 33-42, https://doi.org/10.1016/j.combustflame.2009.09.016, 2010.

Sedlacek, A. J., Buseck, P. R., Adachi, K., Kleinman, L., Onasch, T. B., and Springston, S. R.: Tar balls observed in wildfire plumes are weakly absorbing secondary aerosol, in: ASR Science Team Meeting, Tysons, Virginia, USA, 13-17 March 2017, available at: https://asr.science.energy.gov/meetings/stm/ 2017/presentations/353.pdf (last access: 19 July 2018), 2017.

Sedlacek III, A. J., Buseck, P. R., Adachi, K., Onasch, T. B., Springston, S. R., and Kleinman, L.: Formation and evolution of Tar Balls from Northwestern US wildfires, Atmos. Chem. Phys. Discuss., https://doi.org/10.5194/acp-2018-41, in review, 2018.

Semeniuk, T. A., Wise, M. E., Martin, S. T., Russell, L. M., and Buseck, P. R.: Hygroscopic behavior of aerosol particles from biomass fires using environmental transmis- 
sion electron microscopy, J. Atmos. Chem. 56, 259-273, https://doi.org/10.1007/s10874-006-9055-5, 2007.

Song, J. and Peng, P.: Characterisation of black carbon materials by pyrolysis-gas chromatography-mass spectrometry, J. Anal. Appl. Pyrol., 87, 129-137, https://doi.org/10.1016/j.jaap.2009.11.003, 2010.

Subbalakshmi, Y., Patti, A. F., Lee, G. S. H., and Hooper, M. A.: Structural characterisation of macromolecular organic material in air particulate matter using Py-GC-MS and solid state ${ }^{13} \mathrm{C}-\mathrm{NMR}$., J. Environ. Monitor., 2, 561-565, https://doi.org/10.1039/b005596o, 2000.

Tivanski, A. V., Hopkins, R. J., Tyliszczak, T., and Gilles, M. K.: Oxygenated interface on biomass burn tar balls determined by single particle scanning transmission X-ray microscopy, J. Phys. Chem. A, 111, 5448-5458, https://doi.org/10.1021/jp070155u, 2007.
Tóth, A., Hoffer, A., Nyiro-Kósa, I., Pósfai, M., and Gelencsér, A.: Atmospheric tar balls: aged primary droplets from biomass burning?, Atmos. Chem. Phys., 14, 6669-6675, https://doi.org/10.5194/acp-14-6669-2014, 2014.

Wang, H.-C. and John, W.: Characteristics of the Berner impactor for sampling inorganic ions, Aerosol Sci. Tech., 8, 157-172, https://doi.org/10.1080/02786828808959179, 1988.

Yang, H., Yan, R., Chen, H., Lee, D. H., and Zheng, C.: Characteristics of hemicellulose, cellulose and lignin pyrolysis, Fuel, 86, 1781-1788, https://doi.org/10.1016/j.fuel.2006.12.013, 2007. 